Review article

\title{
Mild cognitive decline. A position statement of the Cognitive Decline Group of the European Innovation Partnership for Active and Healthy Ageing (EIPAHA)
}

\author{
Joao Apostolo ${ }^{\mathrm{a}}$, Carol Holland ${ }^{\mathrm{b}}$, Matthew D.L. O'Connell ${ }^{\mathrm{c}}$, Joanne Feeney ${ }^{\mathrm{d}}$, \\ Rafael Tabares-Seisdedos ${ }^{\mathrm{e}, \mathrm{f}}$, George Tadros ${ }^{\mathrm{g}}$, Elzbieta Campos ${ }^{\mathrm{a}}$, Nadine Santos ${ }^{\mathrm{h}, \mathrm{i}}$, \\ Deirdre A. Robertson ${ }^{\mathrm{c}}$, Maura Marcucci ${ }^{\mathrm{j}}$, Isabel Varela-Nieto ${ }^{\mathrm{k}}$, \\ Benedicto Crespo-Facorro ${ }^{1, \mathrm{~m}, \mathrm{n}}$, Eduard Vieta $^{\circ}$, Esperanza Navarro-Pardo ${ }^{\mathrm{p}}$, \\ Gabriel Selva-Vera ${ }^{\mathrm{e}, \mathrm{f}}$, Vicent Balanzá-Martínez ${ }^{\mathrm{q}}$, Antonio Cano ${ }^{\mathrm{r}, \mathrm{s}, *}$ \\ a Portugal Centre for Evidence Based Practice, Health Sciences Research Unit: Nursing (UICISA: E), Nursing School of Coimbra, Portugal \\ ${ }^{\mathrm{b}}$ Aston Research Centre for Healthy Ageing, Aston University, Birmingham, UK \\ ${ }^{\mathrm{c}}$ Trinity College, Dublin, Ireland \\ d Centre for Public Health, Queen's University Belfast, United Kingdom \\ e Department of Medicine, University of Valencia, INCLIVA, Valencia, Spain \\ ${ }^{\mathrm{f}}$ CIBERSAM, Madrid, Spain \\ ${ }^{g}$ Birmingham \& Solihull Mental Health Foundation Trust, Old Age Psychiatry, Queen Elizabeth Psychiatric Hospital, Birmingham, UK \\ ${ }^{\mathrm{h}}$ Life and Health Sciences Research Institute (ICVS), School of Health Sciences, University of Minho, Braga, Portugal \\ i ICVS/3B's, PT Government Associate Laboratory, Braga, Guimarães, Portugal \\ j Geriatric Unit, Fondazione IRCCS Ca' Granda, Ospedale Maggiore Policlinico \& Department of Clinical Sciences and Community Health, University of Milan, \\ Milan, Italy \\ ${ }^{\mathrm{k}}$ Institute for Biomedical Research, CSIC-UAM and IdiPAZ-CIBERER, Madrid 28029, Spain \\ ${ }^{1}$ Department of Psychiatry, School of Medicine, University of Cantabria, Marqués de Valdecilla Hospital, Santander, Spain \\ $\mathrm{m}$ IDIVAL, Santander, Spain \\ ${ }^{\mathrm{n}}$ CIBERSAM, Madrid, Spain \\ o Barcelona Bipolar Disorders Programme, Hospital Clinic, IDIBAPS, CIBERSAM, University of Barcelona, Barcelona, Spain \\ ${ }^{\mathrm{p}}$ Department of Developmental and Educational Psychology, University of Valencia, Spain \\ ${ }^{q}$ Department of Medicine, La Fe University and Polytechnic Hospital, CIBERSAM, University of Valencia, Valencia, Spain \\ ${ }^{\mathrm{r}}$ Department of Pediatrics, Obstetrics and Gynecology, University of Valencia, Spain \\ s Service of Obstetrics and Gynecology, INCLIVA, Valencia, Spain
}

\section{A R T I C L E I N F O}

Article history:

Received 23 September 2015

Received in revised form 8 October 2015

Accepted 9 October 2015

\section{Keywords:}

Cognition

Mild cognitive decline

Position statement

Cognitive frailty

\begin{abstract}
A B S T R A C T
Introduction: Mild cognitive impairment (MCI) is a term used to describe a level of decline in cognition which is seen as an intermediate stage between normal ageing and dementia, and which many consider to be a prodromal stage of neurodegeneration that may become dementia. That is, it is perceived as a high risk level of cognitive change. The increasing burden of dementia in our society, but also our increasing understanding of its risk factors and potential interventions, require diligent management of $\mathrm{MCI}$ in order to find strategies that produce effective prevention of dementia.

Aim: To update knowledge regarding mild cognitive impairment, and to bring together and appraise evidence about the main features of clinical interest: definitions, prevalence and stability, risk factors, screening, and management and intervention.

Methods: Literature review and consensus of expert opinion.
\end{abstract}

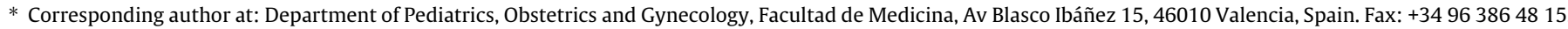
E-mail addresses: apostolo@esenfc.pt (J. Apostolo), c.holland1@aston.ac.uk (C. Holland), oconnem8@tcd.ie (M.D.L. O’Connell), joanne.feeney@qub.ac.uk (J. Feeney), Rafael.Tabares@uv.es (R. Tabares-Seisdedos),gtadros3@yahoo.com

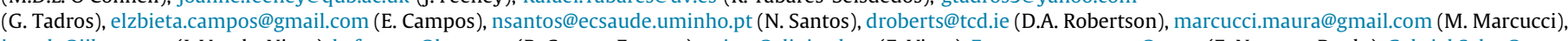

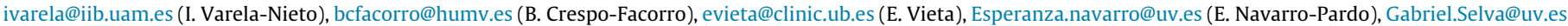
(G. Selva-Vera),Vicente.Balanza@uv.es (V. Balanzá-Martínez),Antonio.Cano@uv.es (A. Cano).
} 
Results and conclusion: MCI describes a level of impairment in which deteriorating cognitive functions still allow for reasonable independent living, including some compensatory strategies. While there is evidence for some early risk factors, there is still a need to more precisely delineate and distinguish early manifestations of frank dementia from cognitive impairment that is less likely to progress to dementia, and furthermore to develop improved prospective evidence for positive response to intervention. An important limitation derives from the scarcity of studies that take MCI as an endpoint. Strategies for effective management suffer from the same limitation, since most studies have focused on dementia. Behavioural changes may represent the most cost-effective approach.

(C) 2015 Elsevier Ireland Ltd. All rights reserved.

\section{Contents}

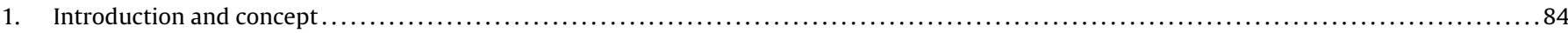

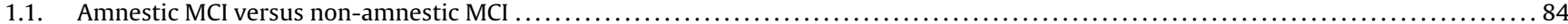

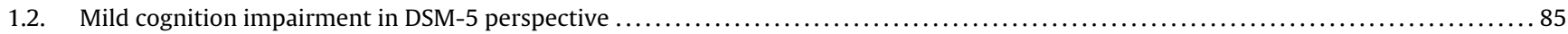

2. Prevalence and stability . . . . . .

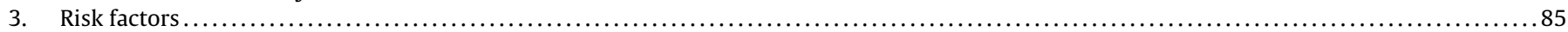

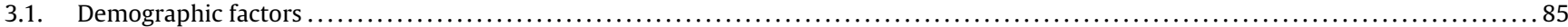

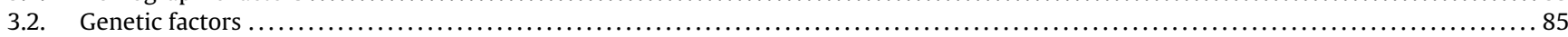

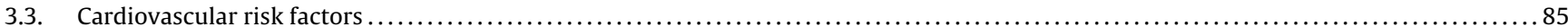

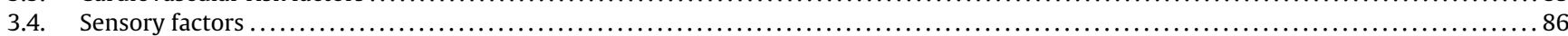

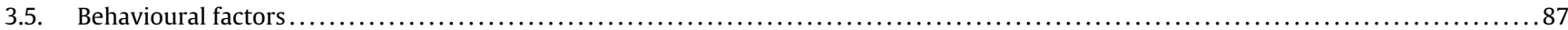

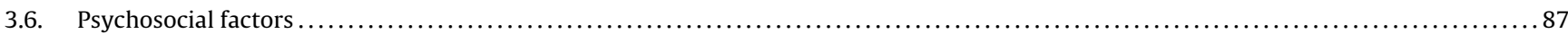

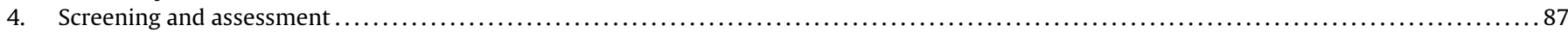

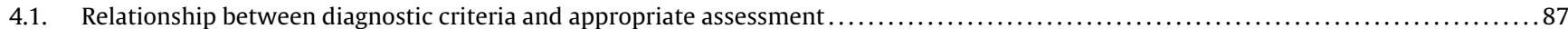

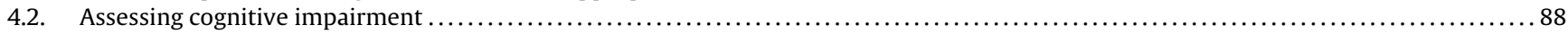

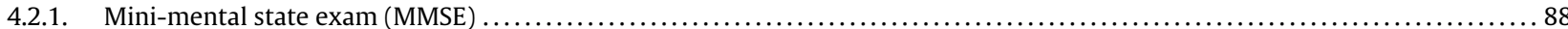

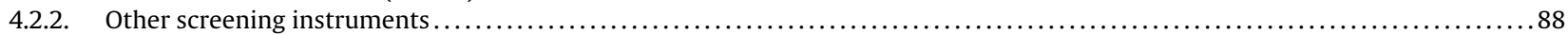

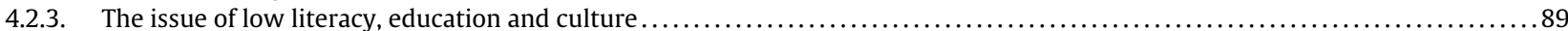

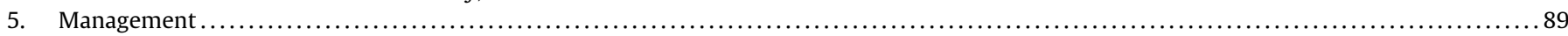

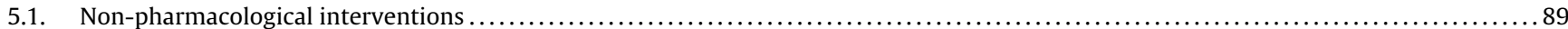

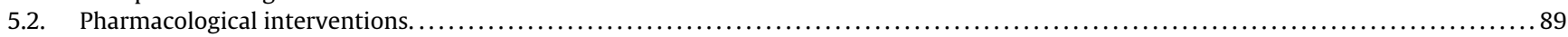

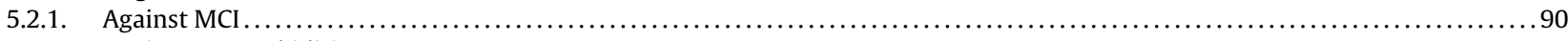

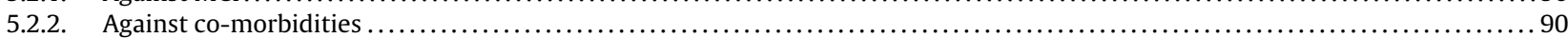

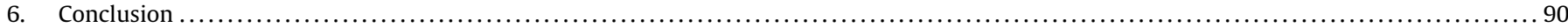

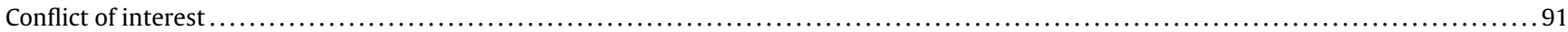

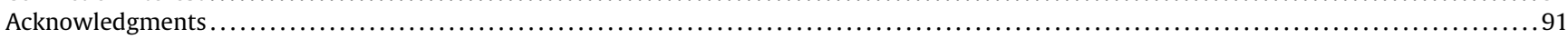

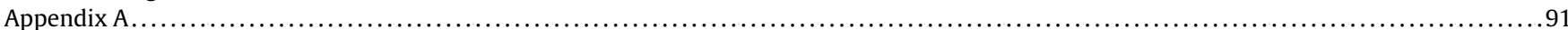

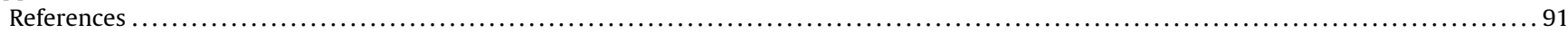

\section{Introduction and concept}

The term mild cognitive impairment $(\mathrm{MCI})$ was introduced as a clinical entity over twenty years ago. Initially, Reisberg and colleagues [1] used this term to describe patients who were at the intermediate stage between normal ageing and dementia state. Later, a set of diagnostic criteria was defined [2]. These diagnostic criteria included abnormal memory function for the person's age and, in association, memory complaints, as well as normal general cognitive function and normal activities of daily living (ADL). In addition, the absence of dementia was inferred, although it was suggested that MCI can constitute a prodromal form of Alzheimerís Disease (AD) [3].

More recently, the investigation from clinical, pathological, genetic, imaging and epidemiological perspectives suggests that $\mathrm{MCI}$ should be expanded to include other cognitive domains such as executive function or visuospatial skills [4-7]. Simultaneously, memory impairment was no longer considered a necessary diagnostic condition. The criteria related to preservation of independence in functional abilities, and to the absence of dementia, were maintained.

According to this new approach [5], MCI was defined by a decline in cognitive functioning that is greater than would be expected for the patient's age and educational background and that goes beyond normal changes seen in ageing. This decline from a previous level can include a variety of cognitive domains, including learning and memory, complex attention, executive functions, language, perceptual-motor domain and social cognition [8], although it is common that decline manifests in a single domain only. Changes in cognitive functioning should be serious enough to be noticed either by the individuals experiencing them, by other people who know the patient well or by a skilled clinician in an appropriate clinical context [5]. For example, impairment in memory can be evidenced by forgetting of important events such as appointments or social engagements, trouble remembering the names of people met recently, word-finding difficulties, trouble remembering the flow of a conversation or the thread of books or movies and an increased tendency to misplace things. While these cognitive changes should not be severe enough to interfere with ADL, complex functional tasks, for example, interpretation of instructions, planning subsequent activities or making decisions, may require the engagement of compensatory strategies by the individual [8].

\subsection{Amnestic MCI versus non-amnestic $M C I$}

Longitudinal studies have indicated that MCI can evolve into different forms of dementia and that this evolution depends on the nature and extent of cognitive impairments experienced in the transitory stage [4]. In order to define better the determinants for making diagnostic decisions, and provide more targeted inter- 
ventions, differentiation between $\mathrm{MCI}$ with (amnestic $\mathrm{MCI}$, a-MCI) or without (non-amnestic $\mathrm{MCI}$, na-MCI) decline in the memory domain has been proposed. Additionally, it is considered relevant to specify whether the diminishing of functioning involves only one cognitive domain or more $[4,9]$.

\subsection{Mild cognition impairment in DSM-5 perspective}

The clinical criteria for $\mathrm{MCI}$ are also considered in The Diagnostic Statistical Manual-5 (DSM-5) [10], although, in this case, a term used for diagnostic purposes is Mild Neurocognitive Disorder (mild NCD). Mild NCD is included together with Major Neurocognitive Disorders (major NCD) in the general category of Neurocognitive Disorders (NCD).

The common feature of NCD is the absence of cognitive impairment at the moment of birth or during early life. Thus, evidence of cognitive decline, necessary to complete the diagnosis, should be based on the previous level of performance. Importantly, the decline in cognitive domains should not appear in the context of delirium or result from other mental disease. This clarification is pertinent, because NCD may result from aetiologies different to neurocognitive disorders. For example, a person with suspected $\mathrm{AD}$ may be classified as having mild NCD due to AD. Other causes may be vascular, traumatic, or others [10].

Conceptual definitions of $\mathrm{MCI}$ have changed over time. Despite intense effort to clarify neuropsychological and clinical profile of this condition, there is still lack of consensus about its neuropathological substratum. It is also necessary to harmonize definitions and labels across working groups and disciplines.

\section{Prevalence and stability}

Reported prevalence of MCI varies, with annual incidence rate ranging from 5.5 to 7.7 percent of persons aged 60 or over [11], and Plassman et al. [12] estimating $22 \%$ of people aged over 71 as having cognitive impairment but not dementia. In terms of the concept of $\mathrm{MCI}$ as an intermediate phase of $\mathrm{AD}$ [6], it has been demonstrated that $15-41 \%$ of $\mathrm{MCI}$ cases per year progress to AD or other dementias [13-15]. For example, in a four year study, Lonie et al. [16] found a mean annual conversion rate of $11 \%$ when assessed using the Addenbrooke's Cognitive Examination criteria, although other authors suggest this may be less (5.8\%) [17].

Conversely, studies have also shown that up to $44 \%$ of patients with $\mathrm{MCI}$ return to a non-MCI diagnosis a year later [14,18] suggesting that it can be viewed as unstable. For example, in an eight year longitudinal study, Anstey et al. [19] found that $45 \%$ of diagnoses were unstable for their group of young-old participants aged 62-64 at baseline. Thus $\mathrm{MCI}$ could be viewed as a transient and high risk phase, and interventions to promote improved health or cognitive functioning could be particularly pertinent for this group. However, these data also indicate that diagnosis or screening of MCI may still be imprecise.

\section{Risk factors}

Studies on risk factors for $\mathrm{MCI}$ suffer from the limitation that the cohorts are almost always contaminated by those cases that are already at an early stage of dementia but do not yet fulfil the necessary criteria for a dementia diagnosis. Of course, this is unavoidable on account of the inherent difficulty in distinguishing between cases of $\mathrm{MCI}$ and those individuals who are suffering from mild dementia. It follows then, that there is a high interest in detecting factors that predict membership of the second group, for example, the APOE4 allele, and there is a large literature on risk factors which examines that issue. This "contamination" also raises the philosophical question of whether $\mathrm{MCI}$ is in itself a different entity to early-stage dementia, or whether all cases of $\mathrm{MCI}$ are in fact preliminary dementias, with diverse aetiologies and varying prognoses depending on the potential for disease progression.

Furthermore, there are also inconsistencies in how different studies define $\mathrm{MCI}$ when attempting to determine risk factors. Many studies simply refer to cognitive decline or cognitive impairment, usually operationalised as a decline in objective cognitive functioning over time, or falling below a threshold score at a single point in time. Finally, there is the related issue of the instability of an $\mathrm{MCI}$ diagnosis, as many cases considered as such no longer meet the criteria at follow-up assessment. These limitations and inconsistencies undoubtedly hamper cross-study comparisons and limit the generalisability of the findings from any single study. This highlights the importance of meta-analysis and related tools in determining risk factors that are robust to these variations until such time as $\mathrm{MCI}$ as a diagnostic entity is more consistently defined and characterised.

The process leading to $\mathrm{MCI}$ is undoubtedly complex, involving multiple, sometimes interrelated, risk factors. There is an expanding literature on the topic. This section will summarise current knowledge on some of the main factors identified with particular reference to studies focusing on $\mathrm{MCI}$ as an outcome. An overview of these risk factors is provided in Table 1.

\subsection{Demographic factors}

Higher age is the best known demographic risk factor, particularly being over the age of 85 [20]. However, estimating the true extent of the association has been problematic, in part because agecorrected normative data for cognitive tests are frequently used to identify individuals with probable $\mathrm{MCl}$. The influence of gender on the development of $\mathrm{MCI}$ is not yet clear. Some studies have demonstrated no gender difference [21], others that males have higher prevalence [22], and others that women have a greater risk of MCI [20].

\subsection{Genetic factors}

In terms of genetic markers, the only widely accepted risk factor is the presence of the APOE4 allele, which is for Alzheimer's dementia [6]. A recent cross-sectional analysis from the Framingham Heart study found an association between APOE4 and MCI, particularly among participants aged 65 and older [23]. Similarly, a study of 46Cuban MCI patients and 28 controls found the frequency of the APOE4 allele to be 10 times higher in patients compared to controls, although the absolute frequency in patients was only $20 \%$ [24].

\subsection{Cardiovascular risk factors}

A large amount of clinical, pathologic and epidemiological evidence supports the association between cardio-metabolic risk factors and cognitive impairment, from its mild expression to overt dementia, including both vascular cognitive impairment [25] and $\mathrm{AD}$, independently of the occurrence of stroke.

Diabetes mellitus, but also higher glucose levels and insulin resistance in non-diabetic individuals, have been linked to a higher risk of cognitive impairment [26-28]. Higher baseline blood pressure [29], cholesterol levels [30], weight and body mass index [31] are associated with faster decline in cognitive performance over time, either when studied individually, clustered in metabolic syndrome or summed up in cardiovascular risk scores [32,33]. However, the available evidence on the association between the traditional vascular risk factors and cognitive impairment is not always consistent and might appear controversial if some elements 
Table 1

Overview of potential mild cognitive impairment risk factors.

\begin{tabular}{|c|c|c|}
\hline \multicolumn{3}{|l|}{ Demographic } \\
\hline & Sex & - Evidence equivocal, studies have suggested higher prevalence in men or women or no gender difference \\
\hline \multicolumn{3}{|l|}{ Genetic } \\
\hline & APOE polymorphism & - APOE-4 allele established risk factor for Alzheimer's disease, associated with MCI \\
\hline \multicolumn{3}{|l|}{ Cardiovascular } \\
\hline & $\begin{array}{l}\text { Diabetes/glucose } \\
\text { metabolism }\end{array}$ & $\begin{array}{l}\text { - Diagnosed diabetes associated with cognitive impairment } \\
\text { - Higher glucose levels and insulin resistance associated with cognitive impairment in non-diabetics }\end{array}$ \\
\hline & Cholesterol levels, BMI & $\begin{array}{l}\text { - Hypercholesterolemia and overweight/obesity in midlife associated with faster declines in cognitive } \\
\text { performance }\end{array}$ \\
\hline & Blood pressure & $\begin{array}{l}\text { - Midlife hypertension associated with cognitive decline } \\
\text { - Possible U-shaped relationship in older adults with low blood pressure also associated } \\
\text { - Repeated bouts of cerebral hypoperfusion associated with orthostatic hypotension, maybe as deleterious as } \\
\text { hypertension }\end{array}$ \\
\hline & Cardiovascular risk burden & $\begin{array}{l}\text { - Cumulative burden of risk factors based on CVD risk scores or presence of metabolic syndrome also } \\
\text { associated }\end{array}$ \\
\hline & Heart rhythm & - Atrial fibrillation associated with poorer cognitive function \\
\hline \multicolumn{3}{|l|}{ Behavioural } \\
\hline & Physical Activity & $\begin{array}{l}\text { - Moderate exercise associated with lower risk of cognitive decline } \\
\text { - Limited studies on } \mathrm{MCI} \text { as outcome }\end{array}$ \\
\hline & Smoking & - Current smoking associated with dementia and with cognitive performance in non-demented individuals \\
\hline & Alcohol & $\begin{array}{l}\text { - Possible U-shaped relationship with moderate drinking associated with lower dementia risk compared to } \\
\text { heavy drinking and abstainers } \\
\text { - Protective effect of alcohol controversial }\end{array}$ \\
\hline \multicolumn{3}{|r|}{ 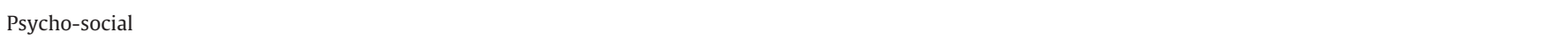 } \\
\hline & Education & $\begin{array}{l}\text { - Lower education associated with higher risk of MCI } \\
\text { - Assessment tools may not be sensitive to small cognitive changes in highly educated people } \\
\text { - Available norms may not be applicable to people with less than secondary level of education }\end{array}$ \\
\hline & Social participation & $\begin{array}{l}\text { - Some evidence larger social networks associated with better cognitive function } \\
\text { - Quality of social networks, frequency of social contact and participation may be more important } \\
\text { - Unclear if good social networks and participation is protective or just concomitant with higher cognitive } \\
\text { function }\end{array}$ \\
\hline & Depression & $\begin{array}{l}\text { - Current and life time history of depressive symptoms associated with higher risk of MCI } \\
\text { - Causal relationships unclear; may be related clinical manifestations of the same underlying process }\end{array}$ \\
\hline
\end{tabular}

$\mathrm{MCI}=$ mild cognitive impairment; $\mathrm{APOE}=$ apolipoprotein $\mathrm{E}$.

are not considered, for example, age at which the risk factor is detected and the study design are important. Longitudinal studies in cognitively healthy midlife participants have found the strongest associations $[34,35]$; however, this may be complicated by the presence of a confounding effect of the decrease of cholesterol levels and weight that might accompany an unhealthy ageing process and particularly dementia in older adults [36]. The duration of exposure to vascular risk also likely plays a role [37].

For certain vascular risk factors, the relationship might not be monotonic. For example, a U-shaped relationship between blood pressure and cognitive decline has been suggested by several studies (e.g. [38]). Repeated episodes of cerebral hypoperfusion associated with orthostatic hypotension are as likely to be deleterious as chronic hypertension [39]. This might be one reason the data on the effect of hypoglycemic therapies, antihypertensive drugs, or statin use on the risk of cognitive impairment are not conclusive $[40,41]$. Finally, effect of vascular risk factors might be modified by the interaction with other risk factors, or with different cognitive disease subtypes, which the existing limited classification criteria might not ascertain.
Several cross-sectional and longitudinal studies have also shown that patients with atrial fibrillation (chronic or paroxysmal) present with worse cognitive and functional performance, and worse trajectories of cognitive test score over time, compared with those in sinus rhythm, even in absence of clinical stroke [42]. Silent cerebral cardio-embolic infarctions may represent the pathological substrate [43]. Mainly because of methodological difficulties, there is no clear evidence regarding a possible protective effect of anticoagulant agents [44].

Encouragingly, most of the major vascular risk factors are modifiable, offering attractive opportunities for disease prevention. For the above mentioned reasons, the timing of any intervention is likely to be crucial to favour success and avoid any iatrogenic harm.

\subsection{Sensory factors}

Sensory deficits are common in older adults with approximately one-third of adults aged 65 and over affected by hearing loss [45]. Oxidative stress, inflammation and neurological degeneration have been implicated in the development of hearing loss, retinal, macu- 
lar and olfactory degeneration - potentially leading to a generalised sensory impairment [46]. This may impact on an individual's independence and ability to interact with their environment, with implications for cognitive function. Hearing impairment in particular has been related to physical frailty and poorer mental health $[47,48]$. The mechanisms linking sensory deficits and cognitive function are still unclear.

\subsection{Behavioural factors}

Over the last decade in particular, there has been considerable interest in physical activity as both a modifiable risk factor and an interventional tool for preventing or ameliorating cognitive impairment. Meta-analyses of prospective studies have shown that physical activity, in particular moderate activity, is associated with a lower risk of cognitive decline [49,50]. Recently, studies have started to examine $\mathrm{MCI}$ as a distinct outcome but the relationship between physical activity and incident cognitive impairment rather than dementia remains somewhat equivocal [51,52]. However, it is clear that exercise is beneficial for cognitive health and thus represents a very good modifiable risk factor to target. A limitation of many investigations in this area to date is the reliance on selfreport instruments to ascertain level of physical activity, which are susceptible to recall and other biases. It is encouraging, however, that studies using objective measurements of activity and measured improvements in cardiovascular fitness are coming to the fore [53].

Evidence that smoking is a risk factor for dementia is mounting. Much of the evidence supports an increased risk for current smokers when compared with individuals who have never smoked, with the risk attributable to previous smoking less clear [54]. To date, investigations of smoking and incident MCI specifically, rather than dementia, have been lacking. However, studies examining the impact of current smoking on subsequent change in cognitive performance suggest that current smoking is associated with cognitive decline in individuals without dementia [55,56].

Many studies have investigated the association between alcohol consumption and risk of cognitive impairment. In the main, the body of evidence supports a reduced risk of dementia for light to moderate drinkers compared with abstainers and heavy drinkers $[57,58]$. Fewer studies have focused on MCI only; among those available, the results have been more mixed, with some studies reporting an U-shaped relationship between alcohol intake and $\mathrm{MCI}$ risk [59] and others finding no protective effect of alcohol intake at any level [11]. However, the concentration and type of alcohol consumed as well as the frequency of intake varies between studies, making cross-comparisons somewhat challenging. More research on this is warranted, in particular where $\mathrm{MCI}$ as the outcome is concerned.

\subsection{Psychosocial factors}

Lower education has been associated with higher risk of $\mathrm{MCI}$ [60] and, unlike age and gender, there is the potential to modify this risk factor at the population level, so it presents an attractive target for risk reduction. There is evidence that education may alter neurobiological substrates to change the brain, by increasing grey matter volume and through continuous activation of the noradrenergic system [61-63]. There are however, some important points to note when endeavouring to interpret epidemiological data on education and risk of $\mathrm{MCI}$ : (i) some assessment measures (e.g. MMSE) are not sensitive enough to detect mild changes in cognition in highly educated people [64]; (ii) according to DSM 5, "norms for neuropsychological testing tend to be available only for broad populations, and thus they may not be easily applicable to individuals with less than high school education or those being evaluated out- side their primary language or culture"; (iii) education level may affect the level of concern, awareness and reporting of cognitive symptoms, and therefore has the potential to influence the likelihood of diagnosis.

A growing body of literature has found that it is not purely formal education that may protect against cognitive decline but mental stimulation in its many forms, including social and cognitive engagement. One of the first studies to show the potentially protective effects of social engagement on cognitive function was that by Bennett et al. who found that older adults with high social networks had higher levels of cognitive function regardless of the level of $A D$ pathology present in their brains at autopsy [65]. This finding has been replicated in other samples (e.g. [66]). However, other studies suggest that high social networks may be concomitant with high cognitive function rather than protective [67]. It is possible that the quality of social engagement is more important than the size of social networks in protecting against cognitive decline [68]. Furthermore, a recent meta-analysis on the association between social relationship and risk of dementia found that social network size and satisfaction with social networks were not associated with cognitive decline but low social participation and less frequent social contact were [69]. Although an encouraging area of investigation, more research into the exact nature of the benefit conferred by social relationships on cognitive health is needed.

Prosocial behaviour may also protect against cognitive impairment by supporting mental health. Among the different types of psychiatric illness, depression has been most consistently associated with $\mathrm{MCI}$ and dementia in the literature. However, the causal nature of the relationship has often been called into question. It has been argued that the three may sit along a continuum, as clinical manifestations of the same underlying neurodegenerative process [70]. There is, nonetheless, considerable support for depression as a risk factor for $\mathrm{MCI}$; for example, a recent study by Chung and colleagues found an association between lifetime history of major depression and amyloid beta deposition in individuals with $\mathrm{MCI}$, regardless of current depressive symptoms [71].

\section{Screening and assessment}

Because of the potential malleability, and the opportunity for intervention, the role of screening and assessment for $\mathrm{MCI}$ is paramount. It is commonly thought that population based screening for cognitive impairments would be unacceptable to individuals and unfeasible to healthcare systems [72], although studies that explore whether there is evidence for such attitudes are not found in the literature, and would be a useful contribution. However, the increasing understanding of risk factors and opportunities for prevention and treatment in the early stages of cognitive decline offer promising avenues for reducing the frequency of dementia in our populations. Clarifying whether earlier screening can be operationalised and simplified for routine clinical use is therefore vital.

\subsection{Relationship between diagnostic criteria and appropriate assessment}

Key criteria for diagnosing MCI were defined by Petersen et al., [2] as (i) a memory complaint (ii) normal activities of daily living (ADL) (iii) normal general cognitive function (iv) abnormal memory for age $(v)$ no dementia. These criteria have since been expanded to include the concept of decline in functions other than memory so that an amnestic and non-amnestic category of $\mathrm{MCl}$ are used (see Section 1). However, studies have also indicated a differentiation between basic activities of daily living (BADL) and instrumental activities of daily living (IADL) such that while people with $\mathrm{MCI}$ do not show any BADL deficits (feeding, bathing or dressing oneself 


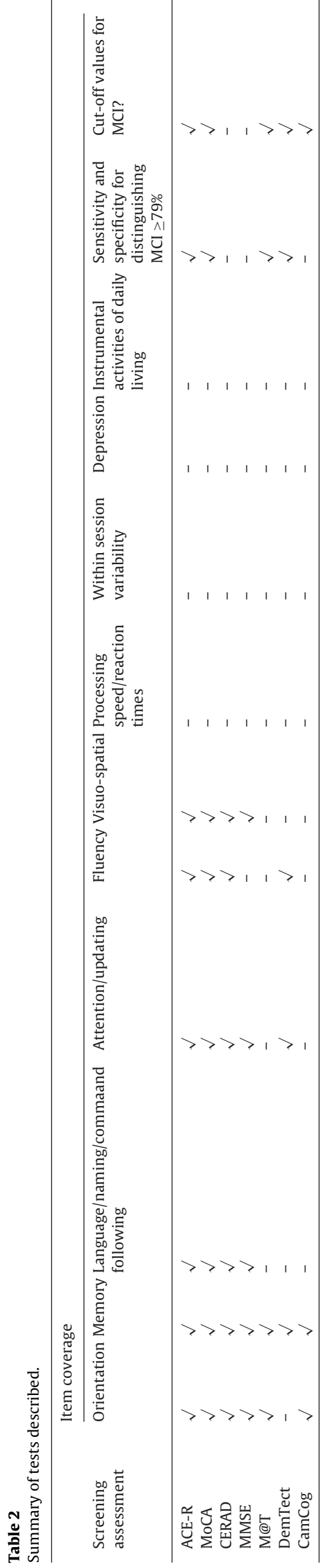

etc), IADL (taking care of one's own finances, medication, shopping, etc) can be impaired before the actual onset of dementia [73,74].

In that context, Winblad et al. [75], in an international consensus report, suggested that the definition should be amended to "preserved BADL and/or minimal impairment in complex instrumental functions", therefore allowing for discrete IADL deficits in MCI. This turns out to be useful. A review and meta-analysis by Jekel et al. [76] indicated that deficits in IADL were very commonly found in people diagnosed with $\mathrm{MCI}$, but with specific emphasis on those IADL that demanded higher cognitive skills. For example, deficits in managing finance were almost universally found. Given that $\mathrm{MCI}$ patients with reduced IADL seem to be more likely to convert to dementia [77-80], any screening and assessment needs to include IADL as a central part, not just because of its predictive utility, but also because of its use in enabling the focused planning of support or rehabilitation strategies to enable continued independence. Indeed, Jekel et al. [76] recommend the use of IADL measures that are specifically designed for $\mathrm{MCI}$, that include performance measures rather than self-declaration or even informant rating, and, in the reality of a short time scale for assessment in a clinical situation, focus on those IADL known to differentiate, that is, those with higher cognitive demand such as financial management. Increasingly, in terms of independence in today's systems, the ability to use technology such as on-line banking or social benefits applications are recommended to be included in new formulations of IADL assessment where appropriate.

Thus in addition to the standard expected cognitive screening, evidence for factors that predict progressive decline, as well as definitions, imply the use of appropriate IADL screening, screening for depression, and screening/medication treatment review for co-morbidities.

\subsection{Assessing cognitive impairment}

\subsubsection{Mini-mental state exam (MMSE)}

Probably the best known brief screening for cognitive impairment internationally is the mini-mental state exam (MMSE [81]). Validated in many countries and languages, this is perhaps the most widely used in both clinical and community settings. It has many weaknesses as the score is affected by level of education and intelligence, inability to monitor change in severe cases, lack of executive functions testing and absence of consideration of cultural differences. Therefore, it is acceptable only as an initial indicator that a person may need further investigation.

The MMSE has been evaluated in a variety of settings, with a meta-analysis by Mitchell [82] suggesting that its sensitivity and specificity varies according to the population, and reported very limited utility of this measure for diagnosing MCI. In a Cochrane review [83] specifically examining the utility of the MMSE for predicting the likelihood of dementia amongst people with $\mathrm{MCI}$, the authors concluded that it was not recommended for this purpose, although with the caveat that decline in the score over repeated testing may prove useful. Use of a "delayed verification" period (usually used in diagnosing dementias, for example, to rule out temporary causes of impairment) would support such validation. Furthermore, given that executive functioning is required to control the allocation of attention and is specifically implicated in compensatory function in situations of mild impairment (e.g. [84]), and it is impaired in a significant proportion of $\mathrm{MCI}$ patients [85], measures such as the MMSE which do not include an executive component would be inappropriate for assessment of MCI.

\subsubsection{Other screening instruments}

In a review of screening in dementia and cognitive impairment, Cullen et al. [86] counsel against recommendations for the universal adoption of specific screening measures in different settings and 
for different purposes, given that a "one size fits all" approach is unlikely to be appropriate. Tools designed for indicating dementia may simply not be appropriate on their own for indicating MCI.

In a review of screening measures, Lonie et al. [87] presented analyses of fifteen screening assessments in terms of their use for identifying $\mathrm{MCl}$. Full descriptions of the sensitivities and specificities can be found in that reference, but it was clear that clinically relevant period re-test ( 6 or 12 months) scores, so important for this population, were absent. Most provided cut-off values to differentiate $\mathrm{MCI}$ from normal ageing (the exception was the CERAD, Consortium to Provide a Registry for Alzheimer's Disease) and one provided demographic adjustment equations (the Montreal Cognitive Assessment, MoCA [88]). The Addenbrookes cognitive examination-revised (ACE-R) [89] and the DemTect [90] had been validated with non-AD dementias and $\mathrm{MCI}$, but most had not. Only four of the fifteen measures were found to have adequate sensitivity and specificity values ( $\geq 79 \%$ ) for distinguishing $\mathrm{MCI}$ from normal healthy age matched controls: these were the ACE-R, DemTect, MoCA and the Memory Alteration Test (M@T, [91]), although of these, only the ACE-R and the MoCA covered all the recommended categories of cognitive function. Lonie et al. [87] reported that adequate sensitivity values, to distinguish a wider range of possible early dementias, were only available for the ACE-R.

However, none of these measures reported specificity values for depression that, as commented above, may be associated with $\mathrm{MCI}$ $[70,92]$. Furthermore, none of the measures included any assessment of speed of processing or reaction time, or of inter-individual variability, with change in both sets of measures being increasingly recognised as predictors of cognitive decline $[93,94]$.

The advent of tablet versions will make the availability of such assessments much more possible in clinical and community settings. Reliability and predictive validity of the measures did not appear to be available in the studies reviewed, although Lonie et al. [87] went on to provide this for the ACE-R.

Table 2 presents these assessment tests and their main features.

\subsubsection{The issue of low literacy, education and culture}

Finally, many of these assessments are of very limited use in populations with very low education and literacy levels, and despite an awareness that dementias are more common amongst people with low education and that this decreases the chance of detecting the earlier stages of dementia or MCI [95], there are few evidenced strategies to deal with this concern. Reviews (e.g. [96]) recommend using a combination of screening and informant information, with an emphasis on reports from a person who knows the patient well, comparing the person's present and past performance.

Of the screening tools used, the most commonly employed were specific items such as verbal fluency or immediate and delayed recall of verbal material. Most included subjective memory complaint. One study delineated education adjusted cut-offs for the MoCA which may be useful for similar samples [97], whereas others recommended informant/interview based measures such as the Clinical Dementia Rating (CRD) scale or the Alzheimer's disease 8 questionnaire (AD8 [98]).

The assessment of cognitive decline in patients from minority ethnicities where they are being assessed in a language which is not their first language, and maybe where social expectations for older people are low, remains a major barrier for clinical practice [99].

\section{Management}

\subsection{Non-pharmacological interventions}

Non-pharmacological strategies constitute an approach that usually acts on modifiable risk factors, social engagement, cogni- tive training, and lifestyle interventions, including physical activity and diet/nutritional interventions.

Interventions focusing on specific risk factors have some uncertainties that need to be considered in the appraisal of the success of the intervention. One important uncertainty is the still open questions about the real impact of their modification, as described above. Also, risk factors are usually related, therefore interventions may usefully target multiple risk factors at once. For example, involvement in group-based exercise might increase physical activity and social engagement while helping to improve cardiovascular risk factors.

Social interaction has been assayed in intervention studies, which have shown reduced risk of progression from mild to severe cognitive impairment associated with a greater frequency of engagement in social activities while mildly impaired $(\mathrm{OR}=0.72$, 95\% CI: 0.55-0.93, $p=0.01$ ) [100]. In a recent meta-analysis, cognition-based intervention was associated with improved global cognitive function in people with $\mathrm{MCI}$ and weak evidence of improvements in the specific domains of executive function and delayed memory [101]. However, these types of intervention rely on the resources to implement and sustain them in practice, and the field has a need to develop evidence-based training which can be sustained by the individuals. In addition, evidence for the role of supportive environments is important. For example, support for active engagement or more general, long-term environmental support and accessible environments can enable social interaction, or a reduction of the demand of instrumental activities of daily living such as shopping.

Physical activity is, as detailed above, a valuable modifiable risk to target. Despite the limitations of the available information, several meta-analyses of longitudinal studies are consistent in the value of physical activity as a risk reduction strategy for MCI [49,50]. Results, however, have been less clear when analyzing the limited number of randomized controlled trials (RCTs). Recent meta-analyses have concluded that physical activity either improves global cognition with no specific effects on executive function and memory [101] or lacks consistent evidence of significant improvements [102] in people with MCI.

Diet is a key factor to promoting brain health [103]. A metaanalysis of available prospective trials $(n=5)$ found that a higher adherence to a Mediterranean-type diet is associated with a reduced risk of $\mathrm{MCI}$ and $\mathrm{AD}$, as well as the progression from $\mathrm{MCI}$ to overt dementia [104]. Mediterranean diet could potentially exert neuroprotective effects via different mechanisms, such as reduction of inflammation and oxidative stress.

In sum, non-pharmacological interventions may be associated with small cognitive benefits for people with $\mathrm{MCI}$ and currently its role can be considered as promising at best. Overall, the methodology of these studies needs further refinement. Most studies are underpowered, and lack of evidence of efficacy is not evidence of lack of efficacy [105]. In addition, consistency across studies is limited by the existence of several diagnostic criteria for $\mathrm{MCI}$, which is a heterogeneous concept [102]. Results are also limited by the diversity of interventions and outcomes and short follow-up periods [105]. Further prospective studies with longer follow-up and highquality RCTs are required to draw definitive conclusions. Future research should also test whether combination of these strategies (multimodal interventions) is associated with more benefits than monotherapy for MCI patients.

\subsection{Pharmacological interventions.}

There is a variety of interventions focusing on trials of medications, often those prescribed to people diagnosed with dementias, or on management of co-morbidities. 


\subsubsection{Against $M C I$}

There is no approved treatment for MCI. No drugs have so far shown evidence to reverse cognitive impairment [106]. However, given the heterogeneity of $\mathrm{MCI}$, further studies testing different compounds in all subtypes of $\mathrm{MCI}$ are necessary to draw clear conclusions. However, the instability and spontaneous reversion to non-MCI levels of cognition already mentioned ( $44 \%$ within a year) $[14,18]$ adds difficulty to the interpretation of results.

5.2.1.1. Acetylcholinesterase inhibitors. Cholinergic deficits have been identified as a pathophysiological origin of $A D$, suggesting the use of acetylcholinesterase inhibitors to slow down the progression of $\mathrm{MCl}$. Although one study [107] showed a positive significant effect of donepezil on cognition, this drug, widely used in $A D$, has not demonstrated to be effective in decreasing the risk of progression from MCI to dementia over 1-3 years [108] nor in having significant effect on cognition over the short term [109].

Concerning galantamine, one study did not show a positive effect on cognition at 16 weeks [110] and another [111] did not demonstrate benefits on the progression to dementia. Finally, a further study with rivastigmine [112] did not improve cognitive performance nor prevent conversion to dementia within 4 years.

In addition, significant side effects may appear with the use of these compounds [108]. Hence, after reviewing all these data, there is no evidence to support the use of cholinesterase inhibitors in $\mathrm{MCI}$ [109], although the inclusion of patients on these trials with non AD-related aetiology could have biased or confounded these [113].

Furthermore, concerning acetylcholine related cognitive dysfunction, the loss of nicotinic receptors has been demonstrated in patients with $\mathrm{AD}$, suggesting the possible benefits of nicotinic agonists on cognitive function of patients with MCI. Newhouse et al. [114] provided evidence for nicotine-induced cognitive improvement in non smoking patients with amnestic MCI after 6 months of treatment with transdermal nicotine. Nevertheless larger studies are necessary to confirm this hypothesis.

5.2.1.2. Other pharmacological interventions. Oxidative stress has been associated with neuronal death in areas of the medial temporal lobe in patients with $\mathrm{MCI}$ or $\mathrm{AD}$. The use of antioxidants can neutralize metabolic products which trigger neuronal injury and death via free radicals. These substances have been tested as possible cognitive enhancers in $\mathrm{MCI}$ and $\mathrm{AD}$.

The role of B vitamins has been assayed in several trials, but a recent meta-analysis reported only weak evidence of a beneficial effect on memory and a lack of adequate evidence of an effect on general cognitive function, executive function and attention in people with MCI [115]. One small double-blind study demonstrated that B vitamins appeared to slow cognitive and clinical decline in MCI patients with elevated homocysteine [116].

Ginkgo Biloba, widely used to enhance memory, was studied in a randomized, double-blind, placebo-controlled clinical trial of 3069 community-dwelling older patients, failing to prevent cognitive decline in those with MCI or normal cognition [117], although positive effects have been reported in studies with smaller samples [118].

The use of omega 3 fatty acids such as docosahexaenoic acid (DHA) and eicosapentaenoic acid (EPA) is promising and studies [119] have shown an improvement in depressive symptoms and general function in patients with $\mathrm{MCI}$, although further research is necessary to confirm these data and clarify their specific influence on cognition.

Testosterone supplementation in men has been studied as a possible memory enhancer but the review of several studies suggests that this effect could only be detected in the short term and was restricted to men with low testosterone levels [120-122].
Other compounds, like anti-inflammatory drugs, platelet aggregation inhibitors, or piracetam, have been investigated but the results have been inconclusive [123].

\subsubsection{Against co-morbidities}

Advances in the treatment of comorbidities have been considered as an alternative option to improve outcomes.

Antihypertensive drugs have been shown to help reduce the risk of developing dementia [124], and regular use of oxygen therapy for COPD patients decreases risk of cognitive decline (OR 0.14; $95 \% \mathrm{CI}$ : 0.07-0.27; $p<0.0001$ ) [125]. Thus additional healthcare support, medication review and monitoring may subsequently improve cognitive outcomes for these individuals. However, commonly prescribed medications such as statins which showed some benefits for cognitive decline in observational studies, failed to prove any significant effect in several large RCTs such as The PROSPER Study (PROspective study of pravastatin in the elderly at risk) [126].

Additionally, although patients with $\mathrm{MCI}$ and depression are suggested as being at more than twice the risk of developing $\mathrm{AD}$ than those without depression, the effect of treating depression has been very poorly investigated. One study found that those with depression at baseline seem to respond poorly to anti-depressant medication [127], while another study found that sertraline, a selective serotonin reuptake inhibitor (SSRI), improved performance on tests of attention, episodic memory, and executive function, but only in treatment responders [128].

This also suggests that behavioural intervention or lifestyle change that can improve psychological health could be particularly effective for this high-risk group.

\section{Conclusion}

MCI defines a clinical condition that is important because it identifies an intermediate state in the progression to dementia. The original clinical definition has been extended, although there is still doubt over whether it constitutes a clinical entity per se, or instead, it is only an early manifestation of an eventual dementia.

Risk factors have been defined, and further research is needed to determine clearer indicators that will enable identification of factors that discriminate cases that will progress to dementia. Further research in the area of risk factors is also needed to identify the earliest predictors of impairment. This is because, encouragingly, many of the known risk factors are potentially modifiable, either through behavioural change, pharmaceutical intervention or promoting social engagement, and have already started to inform management and prevention strategies. How, and the extent to which such modifications delay progression of $\mathrm{MCI}$ is an important area for future clinical trials. Furthermore, emerging research methods, such as next generation genetic sequencing and the 'omics' technologies, have the potential to characterise the biological underpinnings of cognitive decline in much greater detail, facilitating the development of novel therapeutics [129].

The debate on screening, including the potential for population screening, is crucial in the European-wide development of prevention and modification strategies. However, further research with improved screening is needed to determine the extent to which the currently observed instability of a diagnosis of $\mathrm{MCI}$ is indeed due to malleability of the condition or simply to imprecise assessment. The concept of providing evidence of change, or decline is central, as is the concomitant assessment of generally preserved independent functioning. The role of co-morbidities and medication should also be considered in a fuller screening, but in brief screenings, it is recommended that at least depression is screened for. Applications for everyday technology such as tablets and smart phones should make it possible for brief screenings to include assessments 
of processing speed or reaction times, and within task variability, both highlighted as highly predictive of potential decline in the literature, with clear links to neurobiological health.

\section{Conflict of interest}

None of the authors have conflict of interest in what concerns the content of this manuscript.

\section{Acknowledgments}

This manuscript has been supported by the grant PI12/02775 from Instituto de Salud Carlos III-Fondo de Investigación Sanitaria, Ministerio de Sanidad y Consumo, Madrid, Spain, and the European Regional Development Fund (ERDF) to AC, and by the project Frailty management Optimisation though EIP AHA Commitments and Utilisation of Stakeholders input (FOCUS) from the EU 3rd Health Programme. PJ-04-2014 Adherence, frailty, integrated care and multi-chronic conditions to JA, CH, MM and AC.

Instituto de Salud Carlos III- Fondo de Investigación Sanitaria is an agency sustained by the Spanish government. The EU 3rd Health Programme has been issued by the DG Santé of the European Commission.

\section{Appendix A}

This article is on behalf of the Cognitive Decline sub-group of the Action 3 Group-European Innovation Partnership for Active and Healthy Ageing, coordinated by Prof. Antonio Cano, University of Valencia, Spain.

Co-authors from the Cognitive Decline subgroup of the A3 Action Group in European Innovation Partnership for Active and Healthy Ageing (EIPAHA):

- Laura Calzá, Health Sciences and Technologies-Interdepartmental Center for Industrial Research (CIRI-SDV), University of Bologna, Italy; Pharmacy and Biotechnology (FaBiT), University of Bologna, Italy.

- Maria da Graça Pinto, Faculty of Arts and Humanities of University of Porto, Portugal.

- Raúl Lopez-Anton, Department of Psychology and Sociology. University of Zaragoza, Zaragoza, Spain; ISS-Aragón, Zaragoza, Spain.

- Antonio Lobo, Department of Medicine and Psychiatry, University of Zaragoza, Zaragoza, Spain; ISS-Aragón, Zaragoza, Spain. CIBERSAM, Spain.

- João O. Malva, Faculty of Medicine, University of Coimbra, Portugal-Ageing@Coimbra Reference Site, Coimbra, Portugal.

- Dina Popovic, Barcelona Bipolar Disorders Programme, Hospital Clinic, IDIBAPS, CIBERSAM, University of Barcelona, Barcelona, Spain.

- Mónica Sousa-University of Aveiro, Aveiro, Portugal.

- Vicente Felipo, Laboratory of Neurobiology, Centro de Investigación Príncipe Felipe, Eduardo Primo Yúfera, Valencia, Spain.

- Carmina Montoliu, Research Foundation INCLIVA, Valencia, Spain.

- Massimo di Girolamo, Unione Sportiva ACLI, Roma, Italy.

- Stefania Pazzi, ${ }^{e}$ Consorzio di Bioingegneria e Informatica Medica -CBIM, Pavia, Italy.

- James Brown, British Society for Research on Ageing, Aston University, Birmingham, UK.

- Ramón Estévez, Department of Organic Chemistry, University of Santiago de Compostela, Santiago de Compostela, Spain.

- Ernesto Palummeri, Department of Gerontology and Musculoskeletal Sciences, Galliera Hospital, Genoa, Italy.

- Dina Popovic, Bipolar Disorders Program, IDIBAPS, CIBERSAM, University of Barcelona, Barcelona, Spain.
- Amelia Rauter, Chemistry and Biochemistry Centre, School of Sciences, University of Lisbon, Lisbon, Portugal.

- Chariklia Tziraki, Research Department, Community Clubs for Elders, Jerusalem, Israel.

\section{References}

[1] B. Reisberg, S. Ferris, M.J. de Leon, E.S. Franssen, A. Kluger, P. Mir, et al., Stage-specific behavioral, cognitive, and in vivo changes in community residing subjects with age-associated memory impairment and primary degenerative dementia of the Alzheimer type, Drug Dev. Res. 15 (1988) $101-114$

[2] R.C. Petersen, G.E. Smith, S.C. Warring, R.J. Ivnik, E.G. Tangalos, E. Kokmen, Mild cognitive impairment: clinical characterization and outcome, Arch. Neurol. 56 (1999) 303-308.

[3] R.C. Petersen, R. Doody, A. Kurz, R.C. Mohs, J.C. Morris, P.V. Rabins, et al., Current concepts in mild cognitive impairment, Arch. Neurol. 58 (2001) 1985-1992.

[4] R.C. Petersen, Mild cognitive impairment as a diagnostic entity, J. Intern. Med. 256 (2004) 183-194.

[5] R.C. Petersen, R.O. Roberts, D.S. Knopman, B.F. Boeve, Y.E. Geda, R. Ivnik, et al., Mild cognitive impairment: ten years later, Arch. Neurol. 66 (2009) $1447-1455$

[6] M. Albert, S. DeKosky, D. Dickson, B. Dubois, H. Feldman, N. Fox, et al., The diagnosis of mild cognitive impairment due to Alzheimer's disease: recommendations from the National Institute on Aging-Alzheimer's Association workgroups on diagnostic guidelines for Alzheimer's disease, Alzheimer's Dement. 7 (2011) 270-279.

[7] F. Portet, P.J. Ousset, P.J. Visser, G.B. Frisoni, F. Nobli, Ph Scheltens, et al., Mild cognitive impairment (MCI) in medical practice: a critical review of the concept and new diagnostic procedure. Report of the MCI Working Group of the European Consortium on Alzheimer's disease, J. Neurol. Neurosurg. Psychiatry 77 (2006) 714-718.

[8] D.S. Knopman, R.C. Petersen, Mild cognitive impairment and mild dementia: a clinical perspective, Mayo Clin. Proc. 89 (2014) 1452-1459.

[9] R.C. Petersen, B. Caracciolo, C. Brayne, S. Gauthier, V. Jelic, L. Fratiglioni, Mild cognitive impairment: a concept in evolution, J. Intern. Med. 275 (2014) 214-228.

[10] American Psychiatric Association, Diagnostic and Statistical Manual of Mental Disorders, fifth ed., American Psychiatric Association, Washington, DC, 2013.

[11] T. Luck, M. Luppa, S. Briel, S.G. Riedel-Heller, Incidence of mild cognitive impairment: a systematic review, Dement. Geriatr. Cogn. 29 (2010) $164-175$.

[12] B.L. Plassman, K.M. Langa, G.G. Fisher, S.G. Heeringa, D.R. Weir, M.B. Ofstedal, et al., Prevalence of cognitive impairment without dementia in the United States, Ann. Intern. Med. 148 (2008) 427-434.

[13] D. Geslani, M.C. Tierney, N. Herrmann, J. Szalai, Mild cognitive impairment: an operational definition and its conversion rate to Alzheimer's disease, Dement. Geriatr. Cogn. 19 (2005) 383-389.

[14] K. Ritchie, Mild cognitive impairment: an epidemiological perspective, Dialogues Clin. Neurosci. 6 (2004) 401-408

[15] S. Gauthier, B. Reisberg, M. Zaudig, R.C. Petersen, K. Ritchie, K. Broich, et al., Mild cognitive impairment, Lancet 367 (2006) 1262-1270.

[16] J.A. Lonie, M.A. Parra-Rodriguez, K.M. Tierney, L.L. Herrmann, C. Donaghey R.E. O'Carroll, et al., Predicting outcome in mild cognitive impairment: 4-year follow-up study, Brit. J. Psychiatry 197 (2010) 135-140.

[17] A.J. Mitchell, M. Shire-Feshki, Temporal trends in the long term risk of progression of mild cognitive impairment: a pooled analysis, J. Neurol. Neurosurg. Psychiatry 79 (2008) 1386-1391.

[18] M. Ganguli, H.H. Dodge, C. Shen, S.T. DeKosky, Mild cognitive impairment, amnestic type: an epdiemiological study, Neurology 63 (2004) 115-121.

[19] K.J. Anstey, N. Cherbin, R. Eramudugolla, K. Sargent-Cox, S. Easteal, R. Kumar, et al., Characterizing mild cognitive disorders in the young-old over 8 years: prevalence, estimated incidence, stability of diagnosis and impact on IADLs, Alzheimers Dement. 9 (2013) 640-648.

[20] T. Luck, S.G. Riedel-Heller, M. Luppa, B. Wiese, A. Wollny, M. Wagner, et al. Risk factors for incident mild cognitive impairment-results from the german study on ageing, cognition and dementia in primary care patients (AgeCoDe), Acta Psychiatr. Scand. 121 (2010) 260-272.

[21] J.S. Robertson, C. Szoeke, A. Rembach, D. Ames, No gender differences in rates of conversion from cognitively healthy to mci or ad over 18 months: data from the aibl cohort, Alzheimers Dement. 10 (4) (2014) P680, Avaliable from: http://doi.org/10.1016/j.jalz.2014.05.1232.

[22] R.C. Petersen, R.O. Roberts, D.S. Knopman, Y.E. Geda, R.H. Cha, V.S. Pankratz, et al., Prevalence of mild cognitive impairment is higher in men: the Mayo Clinic Study of Aging, Neurology 75 (2010) 889-897.

[23] A.L. Jefferson, A.S. Beiser, S. Seshadri, P.A. Wolf, R. Au, APOE and mild cognitive impairment: the Framingham Heart Study, Age Ageing 44 (2015) 307-311.

[24] V.M. Suárez, Y. Fernández, E.d.C.R. López, D.H. Clarke, M.A. Bobes, A.M Riverón, et al., Apolipoprotein e Alleles in Cuban patients with mild cognitive impairment, Am. J. Alzheimers Dis. Other Dement. 29 (2014) 236-241. 
[25] P.B. Gorelick, A. Scuteri, S.E. Black, C. Decarli, S.M. Greenberg, C. Iadecola, et al., Vascular contributions to cognitive impairment and dementia: a statement for healthcare professionals from the American Heart Association/American Stroke Association, Stroke 42 (2011) 2672-2713.

[26] A.M. Rawlings, A.R. Sharrett, A.L. Schneider, J. Coresh, M. Albert, D. Couper, et al., Diabetes in midlife and cognitive change over 20 years: a cohort study, Ann. Intern. Med. 161 (2014) 785-793.

[27] P.K. Crane, R. Walker, R.A. Hubbard, Ge Li, D.M. Nathan, H. Zheng, et al., Glucose levels and risk of dementia, N. Engl. J. Med. 369 (2013) 540-548.

[28] T.E. Kim, D.H. Lee, Y.J. Kim, J.O. Mok, Ch.L. Kim, J.H. Park, et al., The relationship between cognitive performance and insulin resistance in non-diabetic patients with mild cognitive impairment, Int. J. Geriatr. Psychiatry 30 (2015) 551-557.

[29] T.O. Obisesan, O.A. Obisesan, S. Martins, L. Alamgir, V. Bond, C. Maxwell, et al., High blood pressure, hypertension, and high pulse pressure are associated with poorer cognitive function in persons aged 60 and older: the Third National Health and Nutrition Examination Survey, J. Am. Geriatr. Soc. 56 (2008) 501-509.

[30] A. Solomon, I. Ka ${ }^{\circ}$ reholt, T. Ngandu, B. Winbland, A. Nissinen, J. Tuomilehto, et al., Serum cholesterol changes after midlife and late-life cognition: twenty-one-year follow-up study, Neurology 68 (2007) 751-756.

[31] M. Cournot, J.C. Marquieí, D. Ansiau, C. Martinaud, H. Fonds, J. Ferrières, et al., Relation between body mass index and cognitive function in healthy middle-aged men and women, Neurology 67 (2006) 1208-1214.

[32] K. Yaffe, A.L. Weston, T. Blackwell, K.A. Krueger, The metabolic syndrome and development of cognitive impairment among older women, Arch. Neurol. 66 (2009) 324-328.

[33] A.L. Jefferson, T.J. Hohman, D. Liu, S. Haj-Hassan, K.A. Gifford, E.M. Benson, et al., Adverse vascular risk is related to cognitive decline in older adults, J. Alzheimers Dis. 44 (2015) 1361-1373.

[34] S. Debette, S. Seshadri, A. Beiser, R. Au, J.J. Himali, C. Palumbo, et al., Midlife vascular risk factor exposure accelerates structural brain aging and cognitive decline, Neurology 77 (2011) 461-468.

[35] K. Yaffe, E. Vittinghoff, M.J. Pletcher, T.D. Hoang, L.J. Launer, R. Whitmer, et al., Early adult to midlife cardiovascular risk factors and cognitive function, Circulation 129 (2014) 1560-1567

[36] J.M. Burns, D.K. Johnson, A. Watts, R.H. Swerdlow, W.M. Brooks, Reduced lean mass in early Alzheimer disease and its association with brain atrophy, Arch. Neurol. 67 (2010) 428-433.

[37] L.L. Beason-Held, A. Moghekar, A.B. Zonderman, M.A. Kraut, S.M. Resnick, Longitudinal changes in cerebral blood flow in the older hypertensive brain, Stroke 38 (2007) 1766-1773.

[38] J.S. Elkins, K. Yaffe, J.A. Cauley, H.A. Fink, T.A. Hillier, S.C. Johnston, Pre-existing hypertension and the impact of stroke on cognitive function, Ann. Neurol. 58 (2005) 68-74.

[39] S. Elmsta ${ }^{\circ}$ hl, E. Widerström, Orthostatic intolerance predicts mild cognitive impairment: incidence of mild cognitive impairment and dementia from the Swedish general population cohort Good Aging in Ska ne, Clin. Intervent. Aging 9 (2014) 1993-2002.

[40] L.J. Launer, M.E. Miller, J.D. Williamson, R.M. Lazar, H.C. Gerstein, A.M. Murray, et al., Effects of intensive glucose lowering on brain structure and function in people with type 2 diabetes (ACCORD MIND): a randomised open-label substudy, Lancet Neurol. 10 (2011) 969-977.

[41] B. McGuinness, D. Craig, R. Bullock, P. Passmore, Statins for the prevention of dementia, Cochrane Database Syst. Rev. 15 (April (2)) (2009) CD003160, http://dx.doi.org/10.1002/14651858.CD003160.pub2.

[42] S. Kalantarian, T.A. Stern, M. Mansour, J.N. Ruskin, Cognitive impairment associated with atrial fibrillation: a meta-analysis, Ann. Intern. Med. 158 (2013) 338-346

[43] S. Kalantarian, H. Ay, R.L. Gollub, H. Lee, K. Retzepi, M. Mansour, et al, Association between atrial fibrillation and silent cerebral infarctions: a systematic review and meta-analysis, Ann. Intern. Med. 161 (2014) 650-658.

[44] J. Ball, M.J. Carrington, S. Stewart, SAFETY investigators. Mild cognitive impairment in high-risk patients with chronic atrial fibrillation: a forgotten component of clinical management? Heart 99 (2013) 542-547.

[45] http://www.who.int/topics/deafness/en/, (accessed 15.09.15).

[46] D.W. Belsky, A. Caspi, R. Houts, H.J. Cohen, D.L. Corcoran, A. Danese, et al., Quantification of biological aging in young adults, Proc. Natl. Acad. Sci. U. S. A. 112 (2015) E4104-E4110.

[47] C. Heine, C.J. Browning, Mental health and dual sensory loss in older adults: a systematic review, Front. Aging Neurosci. 6 (2014) 83.

[48] R.J. Kamil, L. Li, F.R. Lin, Association between hearing impairment and frailty in older adults, J. Am. Geriatr. Soc. 62 (2014) 1186-1188.

[49] S.J. Blondell, R. Hammersley-Mather, J.L. Veerman, Does physical activity prevent cognitive decline and dementia? A systematic review and meta-analysis of longitudinal studies, BMC Public Health 14 (2014) 510, http://dx.doi.org/10.1186/1471-2458-14-510.

[50] F. Sofi, D. Valecchi, D. Bacci, R. Abbate, G.F. Gensini, A. Casini, et al., Physical activity and risk of cognitive decline: a meta-analysis of prospective studies, J. Intern. Med. 269 (2010) 107-117.

[51] Y.E. Geda, R.O. Roberts, D.S. Knopman, T.J. Christianson, V.S. Pankratz, R.J. Ivnik, et al., Physical exercise, aging, and mild cognitive impairment: a population-based study, Arch. Neurol. 67 (2010) 80-86.

[52] J. Verghese, A. LeValley, C. Derby, G. Kuslansky, M. Katz, C. Hall, et al., Leisure activities and the risk of amnestic mild cognitive impairment in the elderly, Neurology 66 (2006) 821-827.
[53] G.E. Schlosser Covell, C.R. Hoffman-Snyder, K.E. Wellik, B.K. Woodruff, Y.E. Geda, R.J. Caselli, et al., Physical activity level and future risk of mild cognitive impairment or dementia: a critically appraised topic, Neurologist 19 (2015) 89-91.

[54] K.J. Anstey, C. von Sanden, A. Salim, R. O’Kearney, Smoking as a risk factor for dementia and cognitive decline: a meta-analysis of prospective studies, Am. J. Epidemiol. 166 (2007) 367-378.

[55] K.A. Arntzen, H. Schirmer, T. Wilsgaard, E.B. Mathiesen, Impact of cardiovascular risk factors on cognitive function: the Tromsø Study, Eur. J. Neurol. 18 (2011) 737-743.

[56] S. Sabia, M. Marmot, C. Dufouil, A. Singh-Manoux, Smoking history and cognitive function in middle age from the Whitehall II Study, Arch. Intern. Med. 168 (2008) 1165-1173.

[57] F. Panza, V. Frisardi, D. Seripa, G. Logroscino, A. Santamato, B.P. Imbimbo, et al., Alcohol consumption in mild cognitive impairment and dementia: harmful or neuroprotective? Int. J. Geriatr. Psychiatry 27 (2012) 1218-1238.

[58] R. Peters, J. Peters, J. Warner, N. Beckett, C. Bulpitt, Alcohol, dementia and cognitive decline in the elderly: a systematic review, Age Ageing 37 (2008) $505-512$.

[59] N. Cherbuin, C. Reglade-Meslin, R. Kumar, P. Jacomb, S. Easteal, H. Christensen, et al., Risk factors of transition from normal cognition to mild cognitive disorder: the PATH Through Life Study, Dement. Geriatr. Cogn. Disord. 28 (2009) 47-55.

[60] L. Fratiglioni, B. Winblad, E. von Strauss, Prevention of Alzheimer's disease and dementia. Major findings from the Kungsholmen Project, Physiol. Behav. 92 (2007) 98-104.

[61] E.M. Arenaza-Urquijo, B. Landeau, R. La Joie, K. Mevel, F. Mézenge, A. Perrotin, et al., Relationships between years of education and gray matter volume, metabolism and functional connectivity in healthy elders, Neuroimage 83 (2013) 450-457.

[62] B. Draganski, C. Gaser, G. Kempermann, H.G. Kuhn, J. Winkler, C. Büchel, et al. Temporal and spatial dynamics of brain structure changes during extensive learning, J. Neurosci. 26 (2006) 6314-6317.

[63] I.H. Robertson, A noradrenergic theory of cognitive reserve: implications for Alzheimer's disease, Neurobiol. Aging 34 (2013) 298-308.

[64] O.L. Lopez, Mild Cognitive Impairment Continuum (Minneap Minn) 2013, $19,411-24$.

[65] D.A. Bennett, J.A. Schneider, Y. Tang, S.E. Arnold, R.S. Wilson, The effect of social networks on the relation between Alzheimer's disease pathology and level of cognitive function in old people: a longitudinal cohort study, Lancet Neurol. 5 (2006) 406-412.

[66] V.C. Crooks, J. Lubben, D.B. Petitti, D. Little, V. Chiu, Social network, cognitive function, and dementia incidence among elderly women, Am. J. Public Health 98 (2008) 1221-1227.

[67] R. Stoykova, F. Matharan, J.-F. Dartigues, H. Amieva, Impact of social network on cognitive performances and age-related cognitive decline across a 20-year follow-up, Int. Psychogeriatr. 23 (2011) 1405-1412.

[68] H. Amieva, R. Stoykova, F. Matharan, C. Helmer, T.C. Antonucci, J.-F. Dartigues, What aspects of social network are protective for dementia? Not the quantity but the quality of social interactions is protective up to 15 years later, Psychosom. Med. 72 (2010) 905-911.

[69] J.S. Kuiper, M. Zuidersma, R.C.O. Voshaar, S.U. Zuidema, E.R. van den Heuvel, R.P. Stolk, et al., Social relationships and risk of dementia: a systematic review and meta-analysis of longitudinal cohort studies, Ageing Res. Rev. 22 (2015) 39-57.

[70] F. Panza, V. Frisardi, C. Capurso, A. D’Introno, A.M. Colacicco, B.P. Imbimbo, et al., Late-life depression, mild cognitive impairment, and dementia: possible continuum? Am. J. Geriatr. Psychiatry 18 (2010) 98-116.

[71] J.K. Chung, E. Plitman, S. Nakajima, T.W. Chow, M.M. Chakravarty, F. Caravaggio, et al., Lifetime history of depression predicts increased amyloid- $\beta$ accumulation in patients with mild cognitive impairment, J. Alzheimers Dis. 45 (2015) 907-919.

[72] R. Stewart, Mild cognitive impairment-the continuing challenge of its "real-world" detection and diagnosis, Arch. Med. Res. 43 (2012) 609-614.

[73] L. Nygård, Instrumental activities of daily living: a stepping stone towards Alzheimer's disease diagnosis in subjects with mild cognitive impairment, Acta Neurol. Scand. Suppl. 179 (2003) 42-46

[74] E. Aretouli, J. Brandt, Everyday functioning in mild cognitive impairment and its relationship with executive cognition, Int. J. Geriatr. Psychiatry 25 (2009) 224-233.

[75] B. Winblad, K. Palmer, M. Kivipelto, V. Jelic, L. Fratiglioni, L.O. Wahlund, et al., Mild cognitive impairment: beyond controversies towards a consensus: report of the International Working Group on Mild Cognitive Impairment, J. Intern. Med. 256 (2004) 240-246.

[76] K. Jekel, M. Damiean, C. Wattmo, L. Hausner, R. Bullock, P.J. Connelly, et al., Mild cognitive impairment and deficits in instrumental activities of daily living: a systematic review, Alzheimers Res. Ther. 7 (2015) 17.

[77] K. Pérès, C. Helmer, H. Amieva, J.M. Orgogozo, I. Rouch, J.F. Dartigues, et al. Natural history of decline in instrumental activites of daily living performance over the 10 years preceding the clinical diagnosis of dementia: a prospective population based study, J. Am. Geriatr. Soc. 56 (2008) 37-44.

[78] P.A. Boyle, P.F. Malloy, S. Salloway, D.A. Cahn-Weiner, R. Cohen, J.L. Cummings, Executive dysfunction and apathy predict functional impairment in Alzheimer disease, Am. J. Geriatr. Psychiatry 11 (2003) 214-221. 
[79] P. Chen, G. Ratcliff, S.H. Belle, J.A. Cauley, S.T. DeKosky, M. Ganguli, Cognitive tests that best discriminate between presymptomatic $\mathrm{AD}$ and those who remain non demented, Neurology 55 (2000) 1847-1853.

[80] M.H. Tabert, S.M. Albert, L. Borukhova-Milov, Y. Camacho, G. Pelton, X. Liu, et al., Functional deficits in patients with mild cognitive impairment: prediction of AD, Neurology 58 (2002) 758-764.

[81] M.F. Folstein, S.E. Folstein, P.R. McHugh, Mini-mental state: a practical method for grading the cognitive state of patients for the clinician, J. Psychiatr. Res. 12 (1975) 189-198.

[82] A.J. Mitchell, A meta-analysis of the accuracy of the mini-mental state examination in the detection of dementia and mild cognitive impairment, J. Psychiatr. Res. 43 (2009) 411-431.

[83] I. Arevalo-Rodriguez, N. Smailagic, i. Roque, M. Figuls, A. Ciapponi, E. Sanchez-Perez, A. Giannakou, et al., Mini-mental state examination (MMSE) for the detection of Alzheimer's disease and other dementias in people with mild cognitive impairment (MCI), Cochrane Database Syst. Rev. 5 (3) (2015) CD010783, http://dx.doi.org/10.1002/14651858.CD010783.pub2.

[84] P.A. Reuter-Lorenz, New visions of the aging mind and brain, Trends Cogn. Sci. 6 (2002) 394-400.

[85] G.A. Marshall, D.M. Rentz, M.T. Frey, J.J. Locascio, K.A. Johnson, R.A. Sperling Executive functioning and instrumental activities of daily living in $\mathrm{MCI}$ and AD, Alzeheimers Dement. 7 (2011) 300-308.

[86] B. Cullen, B. O'Neill, J.J. Evans, R.F. Coen, B.A. Lawlor, A review of screening tests for cognitive impairment, J. Neurol. Neurosurg. Psychiatry 78 (2007) 790-799.

[87] J.A. Lonie, K.M. Tierney, K.P. Ebmeier, Screening for mild cognitive impairment: a systematic review, Int. J. Geriatr. Psychiatry 24 (2009) 902-915.

[88] Z.S. Nasreddine, N.A. Phillips, V. Bedirian, S. Charbonneau, V. Whitehead, I. Collin, et al., The Montreal Cognitive Assessment, MOCA: a brief screening tool for mild cognitive impairment, J. Am. Geriatr. Soc. 54 (2005) 695-699.

[89] E. Mioshi, K. Dawson, J. Mitchell, R. Arnold, J.R. Hodges, The Addenbrooke's cognitive examination revised (ACE-R): a brief test battery for dementia screening, Int. J. Geriatr. Psychiatry 21 (2006) 1078-1085

[90] E. Kalbe, J. Kessler, P. Calabrese, R. Smith, A.P. Passmore, M. Brand, et al. DemTect: a new, sensitive cognitive screening test to support the diagnosis of mild cognitive impairment and early dementia, Int. J. Geriatr. Psychiatry 19 (2004) 136-143.

[91] L. Rami, J.L. Molinuevo, R. Sanchez-Valle, B. Bosch, A. Villar, Screening for amnestic mild cognitive impairment and early Alzheimer's disease with M@T (Memory Alteration Test) in the primary care population, Int. J. Geriatr. Psychiatry 22 (2007) 294-304

[92] V. Solfrizzi, A. D’Introno, A.M. Colacicco, C. Capurso, A. Del Parigi, R.J. Caselli, et al., Incident occurrence of depressive symptoms among patients with mild cognitive impairment-the Italian longitudinal study on aging. Dement. Geriatr. Cogn. Disord. 24 (2007) 55-64.

[93] M.H. Tabert, J.J. Many, X. Liu, G.H. Pelton, S. Rosenblum, M. Jacobs, et al. Neuropsychological prediction of conversion to Alzheimer's disease in patients with mild cognitive impairment, Arch. Gen. Psychiatry 63 (2006) 916-924.

[94] M. Lövden, S.-C. Li, Y.L. Shing, U. Lindenberger, Within-person trial-to-trial variability precedes and predicts cognitive decline in old and very old age: longitudinal data from the Berlin Aging Study, Neuropsychologia 45 (2007) $2827-2838$

[95] C.M. Roe, C. Xiong, E. Grant, J.P. Miller, J.C. Morris, Education and reported onset of symptoms among individuals with Alzheimer disease, Arch. Neurol. 65 (2008) 108-111.

[96] M.L. Lim, R. Gomez, C. Koopman, A review of amnestic MCI screening in east/southeast Asian older adults with low education: implications for early informant-clinician collaboration, Int. J. Geriatr. Arch. Gen. Psychiatry 30 (2015) 144-155

[97] J. Lu, D. Li, F. Li, A. Zhou, F. Wang, X. Zuo, et al., Montreal cognitive assessment in detecting cognitive impairment in Chinese elderly individuals: a population based study, J. Geriatr. Psychiatry Neurol. 242 (2011) $184-190$

[98] J.E. Galvin, C.M. Roe, J.C. Morris, Evaluation of cognitive impairment in older adults, Arch. Neurol. 64 (2005) 718-724.

[99] F. Khan, G. Tadros, Complexity in cognitive assessment of elderly British Minority Ethnic groups (BME): cultural perspective, Dementia 13 (2014) $467-482$.

[100] T. Hughes, J.D. Flatt, B. Fu, C. Chang, M. Ganguli, Social engagement and progression from mild to severe cognitive impairment: the MYHAT study, Gerontologist 52 (Suppl. 1) (2012) 537.

[101] C. Wang, J.T. Yu, H.F. Wang, C.C. Tan, X.F. Meng, L. Tan, Non-pharmacologica interventions for patients with mild cognitive impairment: a meta-analysis of randomized controlled trials of cognition-based and exercise interventions, J. Alzheimers Dis. 42 (2014) 663-678.

[102] N. Gates, M.A. Fiatarone Singh, P.S. Sachdev, M. Valenzuela, The effect of exercise training on cognitive function in older adults with mild cognitive impairment: a meta-analysis of randomized controlled trials, Am. J. Geriatr. Psychiatry 21 (2013) 1086-1097.

[103] F. Gómez-Pinilla, Brain foods: the effects of nutrients on brain function, Nat. Rev. Neurosci. 9 (2008) 568-578.
[104] B. Singh, A.K. Parsaik, M.M. Mielke, P.J. Erwin, D.S. Knopman, R.C. Petersen, et al., Association of mediterranean diet with mild cognitive impairment and Alzheimer's disease: a systematic review and meta-analysis, J. Alzheimers Dis. 39 (2014) 271-282.

[105] T. Horr, B. Messinger-Rapport, J.A. Pillai, Systematic review of strengths and limitations of randomized controlled trials for non-pharmacological interventions in mild cognitive impairment: focus on Alzheimer's disease, J. Nutr. Health Aging 19 (2015) 141-153.

[106] S.A. Eshkoor, T.A. Hamid, C.Y. Mun, C.K. Ng, Mild cognitive impairment and its management in older people, Clin. Interv. Aging 10 (2015) 687-693.

[107] R.S. Doody, S. Ferris, S. Salloway, Yijun Sun, R. Goldman, Xu Yikang, Safety and tolerability of donepezil in mild cognitive impairment: open-label extension study, Am. J. Alzheimers Dis. Other Dement. 25 (2010) 155-159.

[108] T.C. Russ, J.R. Morling, Cholinesterase inhibitors for mild cognitive impairment, Cochrane Database Syst. Rev. 9 (2012) CD009132, http://dx.doi. org/10.1002/14651858.CD009132.pub2.

[109] K.M. Langa, D.A. Levine, The diagnosis and management of mild cognitive impairment: a clinical review, JAMA 312 (2014) 2551-2561.

[110] J. Koontz, A. Baskys, Effects of galantamine on working memory and global functioning in patients with mild cognitive impairment: a double-blind placebo-controlled study, Am. J. Alzheimers Dis. Other Dement. 20 (2005) 295-302.

[111] F.J. Gil-Bea, M. Solas, L. Mateos, B. Winblad, M.J. Ramírez, A. Cedazo-Mínguez, Cholinergic hypofunction impairs memory acquisition possibly through hippocampal Arc and BDNF downregulation, Hippocampus 21 (2011) 999-1009.

[112] H.H. Feldman, S. Ferris, B. Winblad, N. Sfikas, L. Mancione, Y. He, et al., Effect of rivastigmine on delay to diagnosis of Alzheimer's disease from mild cognitive impairment: the InDDEx study, Lancet Neurol. 6 (2007) 501-512.

[113] R.C. Petersen, Clinical practice. Mild cognitive impairment, N. Engl. J. Med. 364 (2011) 2227-2234.

[114] P. Newhouse, K. Kellar, P. Aisen, H. White, K. Wesnes, E. Coderre, et al., Nicotine treatment of mild cognitive impairment: a 6-month double-blind pilot clinical trial, Neurology 78 (2012) 91-101.

[115] M.M. Li, J.T. Yu, H.F. Wang, T. Jiang, J. Wang, X.F. Meng, et al., Efficacy of vitamins B supplementation on mild cognitive impairment and Alzheimer's disease: a systematic review and meta-analysis, Curr. Alzheimer Res. 11 (2014) 844-852.

[116] C.A. Jager, A. Oulhaj, R. Jacoby, Cognitive and clinical outcomes of homocysteine-lowering B-vitamin treatment in mild cognitive impairment: a randomized controlled trial, Int. J. Geriatr. Psychiatry 27 (2012) 592-600.

[117] B.E. Snitz, E.S. O’Meara, M.C. Carlson, A.M. Arnold, D.G. Ives, S.R. Rapp, et al., Ginkgo biloba for preventing cognitive decline in older adults, JAMA 302 (2009) 2663-2670.

[118] Z.H. Dong, C.Y. Zhang, B.H. Pu, Effects of ginkgo biloba tablet in treating mild cognitive impairment, Zhongguo Zhong Xi Yi Jie He Za Zhi 32 (2012) $1208-1211$

[119] M. Mazza, M. Pomponi, L. Janiri, Omega-3 fatty acids and antioxidants in neurological and psychiatric diseases: an overview, Prog. Neuropsychopharmacol. Biol. Psychiatry 31 (2007) 12-26.

[120] S. Fukai, M. Akishita, S. Yamada, K. Toba, Y. Ouchi, Effects of testosterone in older men with mild-to-moderate cognitive impairment, J. Am. Geriatr. Soc. 58 (2010) 1419-1421.

[121] C. Vaughan, F.C. Goldstein, J.L. Tenover, Exogenous testosterone alone or with finasteride does not improve measurements of cognition in healthy older men with low serum testosterone, J. Androl. 28 (2007) 875-882.

[122] A.M. Kenny, S. Bellantonio, C.A. Gruman, R.D. Acosta, K.M. Prestwood, Effects of transdermal testosterone on cognitive function and health perception in older men with low bioavailable testosterone levels, J. Gerontol. A: Biol. Sci. Med. Sci. 57 (2002) M321-M325.

[123] T. Karakaya, F. Fußer, J. Schröder, J. Pantel, Pharmacological treatment of mild cognitive impairment as a prodromal syndrome of Alzheimerís disease, Curr. Neuropharmacol. 11 (2013) 102-108.

[124] T. Etgen, D. Sander, H. Bickel, K. Sander, H. Forstl, Cognitive decline: the relevance of diabetes, hyperlipidaemia and hypertension, Br. J. Diab. Vasc. Dis. 10 (2010) 115-122.

[125] N. Thakur, P.D. Blanc, L.J. Julian, E.H. Yelin, P.P. Katz, S. Sidney, et al., COPD and cognitive impairment: the role of hypoxemia and oxygen therapy, Int. J. Chron. Obstruct. Pulmon. Dis. 5 (2010) 263-269.

[126] S. Trompet, P. Van Vliet, A.J. de Creen, J. Jolles, B.M. Buckley, M.B. Murphy, et al., Pravastatin and cognitive functions in the elderly: results of the PROSPER study, J. Neurol. 257 (2010) 85-90.

[127] P.J. Modrego, J. Ferrandez, Depression in patients with mild cognitive impairment increases the risk of developing dementia of Alzheimer type: a prospective cohort study, Arch. Neurol. 61 (2004) 1290-1293.

[128] D.P. Devanand, G.H. Pelton, K. Marston, Y. Camacho, S.P. Roose, Y. Stern, et al., Sertraline treatment of elderly patients with depression and cognitive impairment, Int. J. Geriatr. Psychiatry 18 (2003) 123-130.

[129] L. Shen, P. Thompson, S. Potkin, L. Bertram, L. Farrer, T. Foroud, et al., Genetic analysis of quantitative phenotypes in AD and MCI: imaging, cognition and biomarkers, Brain Imaging Behav. 8 (2014) 183-207. 